\title{
Erhöhte Gefahr für Unfälle
}

Für insulinpflichtige Diabetiker ist die Hypoglykämie ein ständiges Risiko. Dass orale Antidiabetika ähnliche Gefahren bergen können, wird zu wenig beachtet.

Wie häufig sind Hypoglykämien bei Typ-2-Diabetikern und wie beeinträchtigen die Episoden die Sicherheit im Verkehr? USForscher analysierten Unfallstatistiken von 5582 Patienten, bei denen es zu Hypoglykämien gekommen war und verglichen diese mit Daten von 27910 in ähnlicher Weise behandelten Diabetikern ohne Unterzuckerepisoden. Typ-2-Diabetiker mit Hypoglykämieerfahrung nahmen häufiger Sulfonylharnstoffe ein $(38,2$ vs. $25,3 \%)$ und wiesen deutlich mehr Komorbiditäten auf.

\section{Unfallrate um 39\% erhöht}

Die Unfallrate bei Hypoglykämien lag signifikant um 39\% höher als bei Patienten ohne Unterzuckerungen. Auch erlitten $\mathrm{Pa}$ tienten mit Hypoglykämien zu 36\% mehr Stürze und fast doppelt so viele Autounfälle. Jüngere Typ-2-Diabetiker (<65 Jahre) mit Hypoglykämien waren 2,3-mal häufiger in Verkehrsunfälle verwickelt als Altersgenossen ohne Hypoglykämien. Über 65-Jährige hatten ein um 52\% erhöhtes Sturzrisiko infolge von
Unterzuckerung. Dass ältere Diabetiker trotz

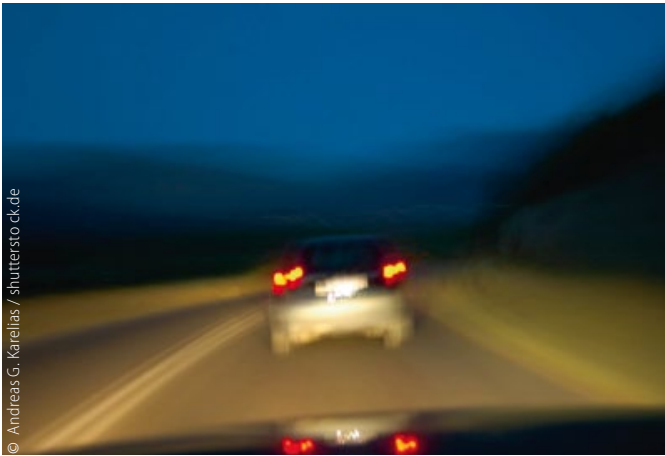

Hypoglykämien viel weniger Unfälle erlitten als jüngere, verwunderte die Autoren nicht. Denn laut früheren Studien passen ältere insulinpflichtige Diabetiker ihre Fahrweise ihren nachlassenden Fähigkeiten an. Sie fahren etwa nur bei Tag Auto, fahren keine langen Strecken und steigen bei schlechter Witterung lieber auf öffentliche Verkehrsmittel um.

Fazit: Auch Typ-2-Diabetiker, die ausschließlich orale Antidiabetika erhalten, müssen von Ärzten über die Gefahren von Hypoglykämien aufgeklärt werden, um Verkehrsunfälle und Stürze zu vermeiden, so die Autoren. Sulfonylharnstoffe steigern das Hypoglykämierisiko deutlich. Die zusätzliche Einnahme eines Glitazons verstärkt das Problem. Dr. Christine Starostzik

Quelle: Ärzte Zeitung basierend auf: Signorovitch JE et al. Diabetes, Obesity and Metabolism 2013;15(4):335-41. doi:10.1111/dom.12031.

\section{Wunschträume, Irrtümer - und Fakten}

\begin{abstract}
Wenn Behauptungen oft wiederholt werden, dann glauben sie die Leute irgendwann, etwa die Thesen zur Adipositas, die verbreitet werden, obwohl jeglicher wissenschaftlicher Beweis fehlt oder gar gegenteilige Erkenntnisse vorliegen. Krista Casazza et al. haben dazu die Massenmedien und die Literatur durchforstet.
\end{abstract}

In das Reich der Märchen, die sich trotz konträrer Datenlage halten, gehören etwa die Annahmen: „Wer in kurzer Zeit abspeckt, erreicht langfristig weniger" oder "eine geringe Kalorienreduktion könne langfristig Gewichtsveränderungen bewirken“. Viele glauben, der Sportunterricht reiche aus, um Kinder vor einer Adipositas zu bewahren oder, dass gestillte Kinder ihr Gewicht später besser regulieren. Manch einer steigert die Frequenz in seinem Sexualleben, weil er meint, er verbrenne dabei bis zu $300 \mathrm{kcal}$. Durchschnittlich werden nur $14 \mathrm{kcal}$ mehr verbraucht als beim Fernsehen. Nicht bewiesen ist auch, dass man durch das Auf und $\mathrm{Ab}$ auf der Waage einen früheren Tod ris- kiert oder, dass die Wohngegend etwas mit der Bereitschaft zur Bewegung zu tun hat. Einige dieser Annahmen mögen teils richtig sein. So tragen der reichliche Obst- und Gemüseverzehr sowie das regelmäßige Frühstück sicher zur Gewichtsregulation bei, jedoch nur, wenn die Gesamtkalorienmenge reduziert wird. Hier sind die Aussagen, die durch Studien belegt sind, gelistet:

- Gene sind wichtig, aber sie sind kein unabwendbares Schicksal, wenn die begünstigenden Faktoren erkannt wurden.

- Durch Kalorienreduktion gelingt die Gewichtsreduktion sehr gut. Ohne weitere Maßnahmen währt das aber nicht lange.

- Jeder profitiert gesundheitlich von mehr körperlicher Aktivität, auch wenn damit keine Gewichtsabnahme erreicht wird.

- Wer sich regelmäßig bewegt, kann sein Gewicht konstant halten. Wer langfristig den Lebensstil beibehält, mit dem er sein Gewicht reduzieren konnte, wird nicht wieder zunehmen.

- Übergewichtige Kinder nehmen erfolgreicher ab und halten das erreichte Gewicht besser, wenn die Eltern und das häusliche Umfeld einbezogen werden.

- Mit strukturierten Mahlzeiten und Nahrungsersatzprodukten wird das Gewicht stärker reduziert als mit scheinbar ganz- 